\title{
Arte, criatividade e desenvolvimento socioemocional de alunos com altas habilidades/ superdotação (AH/SD): considerações a partir de Vigotski
}

\author{
Cristiana Lopes Machado* \\ Tania Stoltz**
}

\section{Resumo}

A educação de alunos com altas habilidades/superdotação (AH/SD) é assegurada pela legislação em vigor que admite esse discente como sujeito de direito à educação especial (BRASIL, 1996; VIRGOLIM, 2012; PISKE, 2014b). Contudo, mesmo a educação especial constituindo-se como um direito, muitos desses alunos encontram-se em situação de exclusão escolar (FREITAS; REICH, 2015). Diante disso, o objetivo do presente estudo é investigar as implicaçóes da arte e da criatividade para o desenvolvimento socioemocional de alunos com AH/SD no contexto inclusivo. Essa investigação se justifica na medida em que procura explicitar o potencial educativo das atividades artísticas e criativas. Este estudo possui caráter qualitativo e é de natureza exploratória. Para tanto, adotamos como instrumentos de coleta de dados a entrevista semiestruturada e a observação. Os participantes desse estudo foram 10 alunos identificados com AH/SD, estudantes da rede de ensino de um município no Estado do Paraná e frequentadores de Sala de Recursos Multifuncional. A partir da análise dos dados, baseada em Aguiar e Ozella (2006), foi possível perceber que a arte e a criatividade constituem-se como instrumentos que auxiliam esse discente a lidar com seu mundo interior, como também possibilitam oportunidades para o emprego do potencial criativo e inovador. Nesse sentido, o estudo aponta para a necessidade de revisão das práticas pedagógicas destinadas aos discentes com potencial superior, como também para a investigação de metodologias de ensino que integrem as atividades artísticas e criativas em suas práticas educacionais.

Palavras-chave: Educação Especial; Altas habilidades/superdotação; Arte.

* Mestranda em Educação pela Universidade Federal do Paraná, Curitiba, Paraná, Brasil.

** Professora doutora da Universidade Federal do Paraná, Curitiba, Paraná, Brasil. Bolsista produtividade do CNPq , processo número 311402/2015-1. 


\section{Art, creativity and social and emotional development among high ability/gifted (HA/G) students: considerations based on Vygotsky}

\section{Abstract}

The education of high ability/gifted (HA/G) students is assured by prevailing legislation which provides gifted children with the right to special education (BRASIL, 1996; VIRGOLIM, 2012; PISKE, 2014b). However, although special education is a right, many gifted children find themselves excluded at school (FREITAS; REICH, 2015). In view of this, the purpose of this study is to investigate the implications of art and creativity to the social and emotional development of HA/G students in an inclusive context. This investigation is justified in that it seeks to explain the educational potential of artistic and creative activities. This is an exploratory qualitative study focussing on a case study. As such the data collection instruments we used were a semi-structured interview. The participants of this study were ten students identified as being HA/G attending public schools in a municipality in the State of Paraná. Based on the analysis of the data it was possible to perceive that art and creativity are an instrument that assists HA/G students in coping with their inner world, as well as providing opportunities for making use of their creative and innovative potential. As such this study points to the need to review teaching practices directed towards students with greater potential, as well as the need to investigate teaching methods which integrate artistic and creative activities in their educational practices.

Keywords: Special education; High ability/giftedness; Art.

\section{Introdução}

A educação especial, sob o enfoque da perspectiva inclusiva, tem como premissa norteadora a valorização da diversidade no contexto escolar, tendo a instituição de ensino o papel de se adaptar e proporcionar medidas pedagógicas que atendam às particularidades do aluno que apresenta necessidades educacionais especiais, como também auxiliar no desenvolvimento de potenciais, respeitar as diferenças e atender aos alunos de acordo com suas necessidades educacionais especiais (BRASIL, 2001).

Nesse sentido, a Política Nacional de Educação Especial na Perspectiva da Educação Inclusiva (BRASIL, 2007), por sua vez, estabelece como objetivo o acesso, a participação e a garantia de aprendizagem dos alunos com deficiência, transtornos globais do desenvolvimento e altas habilidades/superdotação nas escolas regulares, ao passo que também propõe a orientação às instituiçôes de ensino com o objetivo de atender às necessidades educacionais desses discentes.

No que se refere especialmente aos discentes com altas habilidades/superdotação, Sabatella (2008) aponta que em nosso país há estimativa de que teríamos em nossa população quase 9 milhóes de sujeitos talentosos e superdotados. Diante disso, para a autora, esse registro evidencia e justifica a preocupação em elaborar ações educacionais específicas destinadas aos alunos com potencial acima da média. 
Contudo, mesmo que a inclusão escolar desses estudantes seja prática em algumas instituições de ensino de nosso país, alguns alunos que apresentam altas habilidades/superdotação ainda encontram-se excluídos do contexto escolar (FREITAS; RECH, 2015). De acordo com Freitas e Rech (2015), muitos são os aspectos que interferem para que o aluno encontre-se em situação de exclusão, dentre esses, apontam a falta de conhecimento dos docentes em relação a esses alunos, o que, por sua vez, pode dificultar no processo de identificação e atendimento.

Diante disso, percebemos a necessidade de compreender melhor o aluno com altas habilidades/superdotação para que suas habilidades sejam desenvolvidas plenamente. No âmbito escolar, as propostas destinadas a esses estudantes devem considerar o seu desenvolvimento nas dimensóes cognitivas, como também nas áreas afetiva e social (SABATELLA, 2008; VALENTIM, VESTENA, NEUMANN, 2014), uma vez que atender às necessidades desses discentes implica em considerar sua história, os fatores socioculturais e as suas características singulares (FREITAS, 2006).

\section{Oluno com altas habilidades/superdotação (ah/sd): um olhar para o seu desenvolvimento socioemocional}

De acordo com Sabatella (2008), conceituar o fenômeno das altas habilidades/superdotação não se constitui tarefa fácil, sendo a tendência dos estudiosos da área em tornar a definição das altas habilidades/superdotação multidimensional, incluindo não apenas a capacidade cognitiva superior do sujeito, mas uma série de talentos e aptidôes.

Entre os autores (as) que buscam pela redefinição do conceito de AH/SD, temos Guimarães e Ourofino (2007). Para estas autoras, a superdotação é um fenômeno multidimensional, o qual "agrega todas as características de desenvolvimento do indivíduo, abrangendo tanto os aspectos cognitivos quanto características afetivas, neuropsicomotoras e de personalidade" (OUROFINO; GUIMARÃES, 2007, p. 41).

Embora o paradigma sobre a definição da superdotação esteja passando por mudanças, distintos autores (ALENCAR, 2001, 2007, 2012; ALENCAR; FLEITH, 2003, SABATELLA, 2008) indicam que, tanto nas pesquisas quanto no ambiente escolar, o sujeito com altas habilidades/superdotação é reconhecido, usualmente, pela sua capacidade intelectual apurada, ao passo que recebem mais atenção apenas para o desenvolvimento do aspecto cognitivo, em detrimento às outras esferas, como a afetividade e a criatividade, as quais são tấo importantes para um desenvolvimento saudável.

Ao considerar o aluno com potencial elevado como um indivíduo multidimensional, um aspecto que deve ser ponderado, no seu processo de desenvolvimento e formação, são as suas emoçôes e seus sentimentos, pois apesar desse discente ser amplamente reconhecido pela sua capacidade cognitiva, diferentes estudos (ALENCAR, FLEITH, 2001; VIRGOLIM, 2003, 2007; PISKE, STOLTZ, 2012; PISKE, 2013a; PISKE, STOLTZ, CAMARGO, 2014; ALENCAR, 2007, 2014, VALENTIM, VESTENA, NEUMANN, 2014) aquiescem que a dimensão afetiva desse estudante é pouco considerada, mesmo ela sendo um elemento de fundamental importância para o seu processo de desenvolvimento. 
Alencar e Fleith (2001) apontam que, para que as habilidades, potencialidades e talentos desse aluno sejam desenvolvidos de modo pleno, as emoçôes e sentimentos desse discente devem ser consideradas pelas propostas pedagógicas que visam atender a esse público, pois ao ignorar a esfera afetiva do aluno com altas habilidades/superdotação, durante o seu processo educativo, pode haver comprometimento do desenvolvimento de seu potencial (PISKE, 2013 a; PISKE; STOLTZ; CAMARGO, 2014), uma vez que, de acordo com Ourofino e Guimarães (2007), ao tentar compreender seu mundo emocional, este aluno despende muita energia psíquica, a qual, muitas vezes, é incompatível com a idade cronológica do discente, o que, por consequência, pode gerar tensóes no processo de desenvolvimento desse educando.

Diante disso, o presente estudo objetiva identificar quais as implicações da arte e da criatividade no desenvolvimento socioemocional do aluno com altas habilidades/superdotação. Este estudo se justifica na medida em que tenta explicitar o potencial educativo da arte, ao passo que, como já mencionado, o aspecto emocional do sujeito com altas habilidades/superdotação constitui-se numa dimensão essencial a ser desenvolvida para que esse aluno alcance êxito no desenvolvimento de suas potencialidades e habilidades (ALENCAR; FLEITH, 2001; SABATELLA, 2008).

\section{Método}

Esta pesquisa apresenta uma abordagem qualitativa e de caráter exploratório. De acordo com Sampieri, Collado e Lucio (2013), a investigaçáo qualitativa possui características particulares que a distingue das demais perspectivas de pesquisa. Entre essas, destacam que a abordagem qualitativa tem como objetivo compreender em profundidade o objeto de estudo, ao passo que os fenômenos são estudados a partir da perspectiva dos participantes no seu ambiente habitual (BODGAN; BIKLEN, 1994).

O estudo foi realizado numa sala de recursos multifuncional localizada em uma cidade do Estado do Paraná, na regiáo metropolitana de Curitiba. No começo do segundo semestre de 2015 iniciou-se a seleçáo dos participantes do estudo. Inicialmente, a pesquisadora encaminhou para os responsáveis dos alunos o termo de consentimento livre e esclarecido (TCLE) solicitando a autorização para que os discentes pudessem participar da pesquisa. Apenas após os pais/responsáveis assinarem o TCLE e estarem cientes sobre os objetivos do estudo deu-se início à coleta de dados.

A princípio esta pesquisa tinha como propósito coletar dados de todos os alunos matriculados num período do atendimento educacional especializado, no total de 20 alunos. Contudo, alguns estudantes náo retornaram com seus termos de consentimento assinados. Dessa maneira, o estudo foi realizado com $50 \%$ dos discentes matriculados em um período da sala de recursos multifuncional.

Assim, participaram da investigação 10 alunos identificados com altas habilidades/superdotaçáo. Dentre os participantes ${ }^{1}, 6$ eram do sexo feminino e 4 do sexo masculino. Os alunos, de modo geral, estudavam em escolas da rede pública de ensino, apenas duas participantes estudavam em instituiçóes particulares. Os discentes têm idade média entre 8 e 12 anos, sendo um grupo bastante heterogêneo quanto a interesses e habilidades. 
Os dados foram coletados através de entrevistas semiestruturadas e observaçóes na sala de recursos. As entrevistas com os alunos foram compostas por 22 perguntas, divididas em temas, cujo objetivo era analisar questóes referentes ao aspecto emocional dos alunos superdotados, sua relação afetiva com a escola e sobre a arte na vida destes discentes. As entrevistas foram realizadas individualmente, gravadas e transcritas na íntegra.

A entrevista com roteiro semiestruturado se fez pertinente para este estudo, uma vez que consiste num dos principais meios para a coleta de dados, que permite ao informante a liberdade e espontaneidade necessárias para oferecer respostas que irão enriquecer a investigação (TRIVIÑOS, 2013), ao passo que também possibilita ao investigador obter dados em maior profundidade sobre seu objeto de estudo (GIL, 2009).

Para a análise dos dados foram identificados núcleos de significação a partir do material coletado. Esses núcleos envolvem a apreensão de sentidos e significados contidos nas entrevistas realizadas com os discentes com AH/SD. Os núcleos de significação constituem-se numa ferramenta metodológica para a apreensão de sentidos e significados a partir da fala dos sujeitos. Neste instrumento, o empírico é o ponto de partida, mas tem-se a clareza que é necessário ir além do que as aparências dos dados apresentam, sendo necessário buscar explicaçóes do processo de constituição do objeto de estudo (AGUIAR; OZELLA, 2006).

Para tanto, seguindo a proposta de Aguiar e Ozella (2006, 2013) para a elaboração de núcleos de significação, foram realizadas diversas leituras do material (entrevistas transcritas), com o objetivo de aproximação e organização do mesmo. Após diversas leituras foram destacados os pré-indicadores, isto é, os temas que eram encontrados de modo recorrente no discurso dos participantes do estudo. Com os pré -indicadores destacados, passamos para a fase do processo de sua aglutinaçáo. Neste momento, foram agrupados os pré-indicadores de acordo com sua similaridade, complementaridade e contraposição. Após a compilação dos pré-indicadores e formação dos indicadores, iniciamos o processo de articulação e nomeação com o objetivo de formar os núcleos de significação (AGUIAR, OZELLA, 2006; 2013; AGUIAR, SOARES, MACHADO, 2015).

\section{Resultados e discussões}

Para compreender a temática sobre as implicaçóes da arte e da criatividade para o desenvolvimento afetivo de alunos com altas habilidades/superdotação foram construídos, a partir da análise dos dados, três núcleos de significação, estes são: arte como meio de expressáo do mundo interior (sentimentos e emoçôes), arte e sua relação com a vida dos alunos superdotados e arte como possibilidade de expressáo da criatividade e imaginaçâo.

No primeiro núcleo de significação, arte como meio de expressão do mundo interior (sentimentos e emoçóes), percebe-se que a atividade artística, para os alunos que apresentam altas habilidades/superdotaçáo, constituiu-se como um caminho 
para exprimir aspectos individuais, como indica a fala do participante quando perguntado sobre sua relação com a arte: "eu me sinto bem porque dá pra colocar o que nós sente na folha, ne" (LUIS, 11 ANOS).

A análise desse núcleo também permitiu observar que, além de poder expressar aspectos individuais, a arte constitui-se como um meio para os alunos se sentirem melhor, como observamos no discurso de alguns participantes ao serem indagados se em algum momento de sua vida a arte lhes auxiliou em algum sentido:

Sim, porque (pensa por um momento) porque eu pude fazer alguma atividade de arte para me sentir melhor (SOPHI, 10 ANOS) .

Ajudou... me fez sentir bem, posso me expressar (LUIZA, 9 ANOS).

Além de ser um meio de resiliência, a arte auxilia os alunos com altas habilidades/superdotação a lidarem com seus sentimentos e emoçóes, inclusive em momentos de dificuldade. Como podemos observar na fala dos participantes:

(...) acho que cada música, cada desenho capta um pouco dos seus sentimentos. Se você tá triste você coloca uma música triste, lenta, ou um rock pra desestressar, ou se tá mais animado você coloca uma eletrônica... um pop e faz uns desenhos muito locos (ANA, 11 ANOS).

(...) na hora do desenho eu me sinto mais aliviado, mais tranquilo, eu desestresso. Eu relaxo porque no desenho eu inovo e tiro da cabeça aquelas coisas de texto e coloco minha inspiração pra funcionar (MIGUEL, 10 ANOS).

A constituição do segundo núcleo de significação, arte e sua relação com a vida dos alunos superdotados, refere-se ao desejo desses discentes em terem mais contato com atividades artísticas e criativas no contexto escolar, uma vez que nas entrevistas pôde-se explicitar que pouco espaço é destinado às atividades criativas e artísticas. Como percebemos na fala de um participante:

Pra desenhar, além da aula de artes, se não for por si próprio... (pensa) é bem mais fácil ter na aula de artes, em qualquer outra matéria ou em qualquer outro lugar da escola. (MIGUEL, 10 ANOS).

A análise do terceiro núcleo, arte como possibilidade de expressão da criatividade e imaginação, permitiu perceber que a arte, para os alunos com altas habilidades/superdotação, constitui-se num caminho para o uso da criatividade e imaginação, levando a um maior desenvolvimento, ou seja, para esses discentes o envolvimento com a arte pode ser uma oportunidade de usar a sua imaginação e de objetivar sua criatividade através das atividades artísticas. Como percebemos no discurso dos participantes:

Quando eu "tô" desenhando eu posso fazer de tudo que me vem na cabeça, desde situaçóes de como estar estressado até coisas que minha inspiração me envia pro cérebro. (MIGUEL, 10 ANOS). 
É legal desenhar coisas que você imagina (VITOR, 9 ANOS).

Consegui fazer coisas novas, aprender coisas novas. (JULIANO, 9 ANOS).

A partir da análise dos dados pode-se observar que a arte se manifesta na vida dos estudantes com altas habilidades/superdotação, participantes do estudo, como um elemento necessário em seu cotidiano. Nesse contexto, a atividade artística constitui-se como essencial a esses alunos e os auxilia a superar dificuldades de ordem emocional.

Diante disso, de acordo com Vigotski (2001), a arte esta além do simples contágio de sentimentos, ou seja, a arte ultrapassa o limite de apenas despertar alguma emoção no sujeito, mas, para o referido autor, o envolvimento com a atividade artística constitui-se numa experiência complexa, na qual um sentimento transmuta em algo novo.

Ao constituir-se como uma atividade que não se restringe ao "contágio" de sentimentos, a arte se caracteriza numa atividade cujo objetivo é equilibrar a relação do homem com o seu meio, isto é, em sua relação com o ambiente em que se situa, o sujeito pode encontrar situaçôes que, por sua vez, podem gerar equilíbrio e desequilíbrio. A desarmonia do indivíduo com seu meio define-se pelo acúmulo de energia, a qual não encontra vazão no seu cotidiano, assim, a arte seria um meio do homem superar os sentimentos e emoçôes que não encontram vazão no seu cotidiano. (VIGOTSKI, 2001).

Tratando-se de alunos com altas habilidades/superdotação, estes, apesar de, usualmente, possuírem um potencial intelectual acima da média, não se encontram imunes a dificuldades de ordem emocional (PISKE, 2013a; PISKE, STOLTZ, CAMARGO, 2014; ALENCAR, 2014). Nesse sentido, segundo Landau (2002), a criança superdotada pode encontrar problemas quando há falta de equilíbrio entre o desenvolvimento intelectual e emocional. Para a referida autora, mesmo com a mais alta capacidade intelectual, o aluno superdotado dificilmente alcançará seu pleno desenvolvimento sem a maturidade emocional. De acordo com Landau:

Podemos comparar a criança superdotada ao fundista - o atleta que corre longas distâncias-porque está adiante da maioria. Porém, é muito provável que essa posição de frente evidencie-se mais no aspecto intelectual e a criança encontre-se emocionalmente solitária. Se não formos capaz de ajudá-lo, o superdotado pode desistir, conformar-se ou canalizar suas habilidades para fins destrutivos e anti-sociais. (LANDAU, 2002, p. 27).

Diante disso, percebemos que o aluno com altas habilidades/superdotação, por possuir, muitas vezes, uma discrepância entre os aspectos intelectual e emocional, pode encontrar em seu processo de desenvolvimento situaçóes conflituosas que irão desequilibrar sua relação com o meio em que se situa (ALENCAR, FLEITH, 2001; VIRGOLIM, 2003, 2007; PISKE, 2013a). Dessa maneira, a arte, segundo a perspectiva vigotskiana, poderia ser um instrumento capaz de auxiliar o aluno com potencial superior a superar os momentos de dificuldade, como ressalta o autor: 
(...) a arte é a mais importante concentração de todos os processos biológicos e sociais do indivíduo na sociedade que é um meio de equilibrar o homem com o mundo nos momentos mais críticos e responsáveis da vida. (VIGOTSKI, 2001, p. 328-329).

Dessa maneira, como pontua Vigotski (2001), ao ser uma atividade que contempla tanto a dimensão biológica como a social, a arte constitui-se numa atividade que concentra os distintos aspectos do sistema psicológico, sendo, portanto, uma atividade que "nos revela antes de tudo não como uma reação que economiza, mas como reação que destrói a nossa energia nervosa” (VIGOTSKI, 2001, p. 257).

Nesse sentido, distintos autores apontam que o envolvimento com a atividade artística poderia deflagrar o funcionamento de um sistema de funções superiores, como a percepção, linguagem, pensamento, memória, sentimentos e emoçôes (TOASSA, 2011). Barroco e Superti (2014), por sua vez, aquiescem com Toassa e indicam que, ao possuir um mecanismo próprio capaz de provocar a reação estética, a arte, por evocar distintas capacidades do psiquismo, pode modificar o envolvimento psicológico do sujeito com o objeto do conhecimento, tornando essa relação mais sofisticada.

Assim, pode-se indicar, através da análise internúcleo, que a arte, para os alunos com altas habilidades/superdotação participantes da pesquisa, apresenta-se como uma atividade que permite a expressão da criatividade e também proporciona o envolvimento desses alunos em situaçôes desafiadoras que os impulsionam a fazer algo novo que antes não poderiam realizar, ou seja, que desafiam o seu potencial.

Nesse sentido, de acordo com Vigotski, a atividade criativa (ou criação) se realiza de forma circular e envolve os mais diversos processos psicológicos superiores. Sendo que, primeiramente, envolve a percepção da realidade e a acumulação dessa pela memória. $\mathrm{Na}$ sequência, ocorre a reelaboração desses elementos pela fantasia e imaginação. Nesse processo encontram-se tanto a cognição como a vontade e o afeto. Por último, acontece a objetivação do produto da imaginação, o qual constitui-se em algo novo. (ZANELLA et al, 2003).

Assim, podemos perceber que a imaginação tem participação fundamental no processo criativo. De acordo com Camargo (2013, p.134), a criatividade constitui-se "como um processo que surge da imaginação". A imaginação, por sua vez, constitui-se a partir das experiências adquiridas pelo sujeito, portanto, toda atividade imaginativa é composta por elementos retirados da realidade e das vivências anteriores do sujeito (CAMARGO, 2013; PISKE, STOLTZ, CAMARGO, 2014; STOLTZ et al. 2015).

De acordo com Vigotski (2009), a imaginação não se define como uma atividade ociosa da mente, mas como uma função vital necessária. Assim, o autor ressalta que "toda obra imaginativa constrói-se sempre de elementos tomados da realidade e presentes na experiência anterior da pessoa" (VIGOTSKI, 2009, p. 20). Dessa maneira, ao constituir-se como uma atividade com intrínseca relação com as vivências do sujeito, a imaginaçáo possui sua gênese nos aspectos afetivos do indivíduo. Sendo, portanto, uma atividade com a mais alta expressão da dimensão subjetiva do homem, uma vez que no processo imaginativo buscamos imagens capazes de configurar nossas 
emoções, ao passo que as imagens servem de expressão interna para os sentimentos (CAMARGO, 2013). Nesse sentido, Vigotski ressalta que:

(...) as imagens da fantasia servem de expressão interna dos nossos sentimentos. A desgraça e o luto de uma pessoa são marcados com a cor preta; a alegria, com a branca; a tranqüilidade, com o azul; a rebelião, com o vermelho. As imagens e as fantasias propiciam uma linguagem interior para o nosso sentimento. $\mathrm{O}$ sentimento seleciona elementos isolados da realidade combinando-os numa relação que se determina internamente pelo nosso ânimo, e não externamente, conforme a lógica das imagens. (VIGOTSKI, 2009, p. 26).

Diante disso, a atividade criativa, assim com a atividade artística, define-se como um meio capaz de dar acesso ao homem aos seus sentimentos e emoçôes. De modo que, de acordo com a perspectiva vigotskiana, a criaçáo constitui-se numa necessidade profunda do psiquismo humano, uma vez que possibilita a sublimaçáa de energias negativas (VIGOTSKI, 2010), pois:

(...) a criação como sublimação, ou seja, como transformação de modalidades inferiores de energia psíquica, que não foram utilizadas nem encontradas vazão na atividade normal do organismo, em modalidades superiores. (VIGOTSKI, 2010, p. 337).

Como já mencionado, no que tange à educação de alunos com altas habilidades/superdotação, estes apenas poderão alcançar um pleno desenvolvimento de suas potencialidades e habilidades quando tiverem práticas educativas que contemplem todas as esferas de seu desenvolvimento, tanto os aspectos cognitivos quanto os afetivos (ALENCAR, FLEITH, 2001; ALENCAR, 2007; PISKE, 2013; PISKE, STOLTZ, CAMARGO, 2014). Entretanto, de acordo com Piske (2014), é evidente que o sistema de ensino prioriza as atividades repetitivas, que apelam apenas para a memória, de modo que essas práticas dificultam que alunos com potencial elevado expressem sua criatividade, o que, por consequência, acaba inibindo que a capacidade criadora e inovadora desses alunos sejam desenvolvidas e aprimoradas. Portanto, muitas vezes, as práticas pedagógicas ofertadas nas escolas deixam os alunos com altas habilidades/superdotação desmotivados, o que acaba gerando grande frustração nesses discentes (PISKE; STOLTZ, 2013).

De acordo com Freitas et al (2012), os alunos com altas habilidades/superdotação são inseridos num sistema educacional que têm objetivos e métodos de ensino preestabelecidos, com práticas muitas vezes descontextualizadas e desmotivadoras de seus interesses. Nesse sentido, Alencar e Fleith (2001) apontam que a escola atual, a qual é adepta de práticas baseadas na reprodução de conhecimentos que sobrecarrega a memória dos alunos com informaçôes descontextualizadas, ensino livresco e currículos rígidos, pode contribuir para que o potencial criativo desse aluno seja inibido. Dessa maneira, torna-se um imperativo rever as práticas pedagógicas que são direcionadas aos alunos com altas habilidades/superdotação nas classes regulares, uma vez que a educação especial na perspectiva inclusiva postula que a escola deve adaptar-se às necessidades educacionais desse aluno (BRASIL, 2001). Portanto, a partir da pers- 
pectiva inclusiva, a escola deve também adaptar suas práticas pedagógicas voltadas à educação do aluno com altas habilidades/superdotação.

Outro aspecto observado na relação internúcleos, refere-se ao fato de que os alunos participantes do estudo, de modo geral, indicam que através da arte e da criatividade podem ter acesso ao seu mundo interior, sentimentos e emoçóes. Isso se deve ao fato que as atividades artísticas e criativas mantêm intrínseca relação com a dimensão afetiva do sujeito- e como já mencionamos aqui, os aspectos afetivos, quando integrados à educação, tornam essa relação mais qualitativa.

De acordo com Duarte Jr (1995, 2010, 2012), a linguagem procura captar os sentimentos e emoções humanas de modo que venha a significar e classificar em conceitos. Dessa forma, a linguagem nomeia e classifica os sentimentos em categorias, contudo, não os descreve. Por outro lado, a arte, segundo o referido autor (DUARTE JR., 2012), através de sua forma e seus signos, procura exprimir e simbolizar os sentimentos e emoçóes do indivíduo, de modo que a atividade artística remete aos sentidos advindos do universo dos sentimentos e emoçóes.

Nesse sentido, percebemos que os alunos com altas habilidades/superdotaçáo, de modo geral, parecem utilizar as atividades artísticas e criativas como meio privilegiado para expressão de seu mundo interior, ao mesmo tempo que utilizam esses instrumentos como meio de olhar seus sentimentos e emoçôes individuais, permitindo-lhes, então, a expressão de sua singularidade. Ou seja, há indícios de que por meio da arte e da criatividade, os alunos com potencial superior têm liberdade para "ser o que são".

Assim, as atividades artísticas tornam-se necessárias no âmbito escolar, uma vez que por meio da aproximação com as artes, a estética pode tornar-se um instrumento para a educação do sensível, levando, então, o sujeito a descobrir formas diferentes de perceber o mundo. (CAMARGO; BULGACOV, 2008; STOLTZ, WEGER, 2012, 2015; OLIVEIRA, STOLTZ, 2010; VEIGA; STOLTZ, 2014).

De acordo com Reis et al (2004), a percepção estética é criativa, pois não se limita ao esgotamento daquilo que se percebe, mas procura ampliar as possibilidades de significado daquilo que é percebido, além de constituir-se numa atividade complexa que contempla as distintas funçóes psicológicas. Nesse sentido, a arte torna-se um imperativo no contexto educacional e nas práticas destinadas aos alunos com altas habilidades/superdotação e também aos demais estudantes. Ao ser uma atividade complexa capaz de mudar o comportamento do sujeito (VIGOTSKI, 2010), esta pode vir a ser uma atividade capaz de provocar o seu desenvolvimento, principalmente nos discentes com potencial superior, uma vez que, ao se encontrarem inclusos no sistema regular de ensino, devem receber apoio e adequaçóes que garantam o seu desenvolvimento nas distintas dimensóes (PISKE, 2011; PISKE, STOLTZ, MACHADO, 2014).

Entretanto, de acordo com Zanella et al (2005), a arte e a atividade criativa, de acordo com a perspectiva vigotskiana, não se limita apenas a ser meio de expressão dos sentimentos e emoçóes. Essa, além de objetivar o aspecto afetivo do sujeito, 
também, no seu processo, subjetiva o homem levando-o a produzir novas emoçôes, uma vez que "os sentimentos e emoçôes encontram na arte uma possibilidade de transformação, superação" (ZANELLA et al, 2005, p. 192)

Nesse sentido, a principal função da arte, para Vigotski, seria a possibilidade de proporcionar a catarse. De acordo com o autor bielorrusso, no momento da reação estética, as emoçôes negativas são descarregadas, transformando-se, assim, em emoções positivas, ou seja, na reação estética há uma transformação dos sentimentos e emoçóes do sujeito (TOASSA, 2011). Assim, para Vigotski:

A verdadeira natureza da arte sempre implica algo que transforma, que supera o sentimento comum, e aquele mesmo medo, aquela mesma dor, aquela mesma inquietação, quando suscitadas pela arte, implicam o algo a mais acima daquilo contido. E este algo supera esses sentimentos, elimina esses sentimentos, transforma a sua água em vinho, e assim se realiza a mais importante missão da arte. A arte está para a vida como o vinho está para a uva (...). (VIGOTSKI, 2001, p. 307).

No que se refere à educação de alunos com altas habilidades/superdotação, a arte e as atividades criativas mostram-se como uma alternativa viável para a educação desses discentes, auxiliando-os a lidarem com seus sentimentos e emoçôes, além de possibilitar o uso da imaginação e de seu potencial criativo.

Assim, faz-se necessário repensar as práticas pedagógicas destinadas a esses alunos, com o objetivo de auxiliar no desenvolvimento de suas habilidades e potencialidades, uma vez que nas fases da vida como infância, adolescência e juventude a educação tem o dever de assistir e educar todos os sujeitos, incluindo os com habilidades superiores (GUENTHER, 2006).

\section{Conclusões}

Neste estudo buscou-se identificar quais as implicaçóes da arte e da criatividade para o desenvolvimento socioemocional de alunos com altas habilidades/ superdotação. Com a análise dos dados há indícios de que os alunos utilizam das atividades artísticas e criativas como instrumento para dar vazão aos seus sentimentos e emoções, utilizando a arte e a criatividade como meio de superar dificuldades e situações conflituosas.

Além de utilizarem a arte e as atividades criativas como meio de resiliência, os estudantes com potencial acima da média valem-se das artes como meio de expressão de sua imaginação e potencial inovador e criador. Contudo, mesmo a arte constituindo-se num meio que auxilia o aluno com altas habilidades/superdotação no seu processo de desenvolvimento e possibilita a expressão da imaginação e do potencial criativo, os alunos participantes da pesquisa apontam que a arte e a criatividade estão pouco presentes na escola em que estudam. A escola é vista como adepta de atividades mecânicas, reprodutoras de conteúdos.

Embora afirmem gostar da escola em que estudam e, em sua maioria, afirmem que esta instituição se faz importante em suas vidas, pois pode vir a possibilitar a 
garantia de um bom futuro e a possibilidade de terem acesso a novos conhecimentos, os estudantes participantes do estudo apontam que o ambiente escolar, usualmente, é cansativo, monótono e repetitivo.

Com isso, o presente estudo acredita ainda ser necessário empregar esforços em investigaçóes que procurem integrar as atividades criativas e artísticas nas metodologias de ensino de nossas escolas, principalmente nas práticas destinadas a alunos com potencial elevado, uma vez que esse estudo evidenciou que a arte consiste num meio capaz de auxiliar os alunos com altas habilidades/ superdotaçáo a lidarem com seu mundo interior, ou seja, suas emoçôes e sentimentos. Também se mostra necessário investir em estudos que procurem explicitar o processo de constituição da identidade desses estudantes, com o objetivo de conhecer as características específicas desse segmento de discentes, facilitando a identificação e o atendimento dos alunos com altas habilidades/superdotação no contexto da educação inclusiva.

\section{Referências}

AGUIAR, W. M. J.; OZELLA, S. Núcleos de significação como instrumento para a apreensāo dos sentidos. Psicologia ciência e profissão, São Paulo, v. 26, n. 2, p. 222-245, 2006.

AGUIAR, W. M. J.; OZELLA, S. Apreensão dos sentidos: aprimorando a proposta dos núcleos de significação. Rev. Bras. Est. Pedag, Brasilia, v. 94, n. 2, p. 299-322, 2013.

AGUIAR, W. M. J.; SOARES, J. R.; MACHADO, V. C. Núcleos de significação: uma proposta histórico-dialética de apreensão das significaçóes. Cadernos de Pesquisa, v. 45, n. 155, p. 56- 75, 2015.

ALENCAR, E. S. Criatividade e educaçáo de superdotados. Petrópolis: Editora Vozes, 2001.

ALENCAR, E. S. (a) Características sócio-emocionais do superdotado: questôes atuais. Psicologia em estudo, Maringá, v. 12, n. 2, 2007, 371- 378.

ALENCAR, E. S. (b) Indivíduos com altas habilidades/ superdotação: clarificando conceitos, desfazendo ideias errôneas. In: Fleith, D. S. (org). A construçáo de práticas educacionais para alunos com altas habilidades/ superdotaçáa: orientaçáo a professores. Brasília: Ministério da Educação, Secretaria de Educaçáo Especial, p. 15-23, 2007.

ALENCAR, E. S. O aluno com Altas habilidades na escola inclusiva. In: MOREIRA, L. C.; STOLTZ, T. (Org.) Altas habilidades/superdotação: talento, dotação e educação. Curitiba: Juruá, 2012.

ALENCAR, E. S. Ajustamento emocional e social do superdotado: fatores correlatos. In: PISKE, F. H. R. et al. Altas habilidades/superdotaçáo: criatividade e emoção. Curitiba: Juruá, 2014.

ALENCAR, E. S.; FLEITH, D. S. Superdotados: determinantes educação e ajustamento. 2. ed. São Paulo: EPU, 2001.

ALENCAR, E. S.; FLEITH, D. S. Criatividade: múltiplas perspectivas. 3. ed. Brasília: Editora UnB, 2003.

BARROCO, S. M. S.; SUPERTI, T. Vigotski e o estudo da psicologia da arte: contribuiçōes para o desenvolvimento humano. Psicologia e sociedade, Maringá, v. 26, p. 22-31, 2014.

BRASIL. Lei 9.394 de 20 de dezembro de 1996. Estabelece as diretrizes e bases da educação nacional. Diário Oficial da Uniăo. Brasília: 23 de dezembro de 1996.

BRASIL. Ministério da Educação. Secretaria de Educação Especial. Diretrizes Curriculares Nacionais para a Educaçáo Especial. Brasília, DF, 2001. 79 p.

BRASIL. Ministério da Educação. Secretaria de Educação Especial. Política Nacional de Educaçáo Especial na Perspectiva da Educaçáo Inclusiva. Brasília, DF, 2007. 15 p.

BOGDAN, R.; BIKLEN, S. Investigaçáo qualitativa em educaçáo: uma introdução à teoria e aos métodos. Portugal: Porto Editora, 1994.

CAMARGO. D. Imaginaçấo, criatividade e escola. In: PISKE, F. H. R.; BAHIA, S. Criatividade na escola: o desenvolvimento de potencialidades, altas habilidades/superdotação (AH/SD) e talentos. Curitiba: Juruá, 2013. 
Arte, criatividade e desenvolvimento socioemocional de alunos com altas habilidades/superdotação (ah/sd): considerações a partir de Vigotski

CAMARGO, D.; BULGACOV, Y. L. M. A perspectiva estética e expressiva na escola: articulando conceitos da psicologia sócio- histórica. Psicologia em estudo, Maringá, v.13, n.3, p. 467-475, 2008.

DUARTE JÚNIOR, J. F. Fundamentos estéticos da educaçáo. 4. ed. Campinas: Papirus, 1995.

DUARTE JÚNIOR, J. F. O sentido dos sentidos: a educação (do) sensível. 5. ed. Curitiba: Criar Edições UFPR, 2010.

DUARTE JÚNIOR, J. F. Por que arte- educaçáo? . 22. ed. São Paulo: Papirus editora, 2012.

FLICK, U. Introduçáo a pesquisa qualitativa. 3. ed. Porto Alegre: Artmed, 2009.

FREITAS, S. N. Superdotação/altas habilidades: inclusão educacional, pressupostos e subsídios para a ação docente. In: 29० Reuniáo da Anped - Associação Nacional de Pós-graduação e Pesquisa em Educação, 2006. Minas Gerais. Anais. Caxambu: ANPED, 2006.

FREITAS et al. Alunos com altas habilidades/superdotação: problematizando as tendências pedagógicas tendo em vista as práticas educacionais com estes alunos. Revista Telas, v. 14, n. 28, p. 195- 209, 2012.

FREITAS, S. N.; RECH, A. J. D. Atividades de enriquecimento escolar como estratégias para contribuir com a inclusão escolar dos alunos com altas habilidades/superdotação. Educaçáo especial: diferenças, currículo e processos de ensino e aprendizagem II, v. 23, n. 30, p.1-17, 2015.

GIL, A. C. Estudo de caso: fundamentação cientifica subsídios para coleta e análise de dados como redigir o relatório. 1. ed. São Paulo: Atlas, 2009.

GUENTHER, Z. C. Desenvolver capacidades e talentos: um conceito de inclusão. 2. ed. Petrópolis: Editora Vozes, 2006.

GUIMARÁES, T. G.; OUROFINO, V. T. A. T., Características intelectuais, emocionais e sociais do aluno com Altas habilidades/ Superdotação. In: Fleith, D. S. (Org). A construçáo de práticas educacionais para alunos com altas habilidades/superdotaçáo: orientação a professores. Brasília: Ministério da Educação, Secretaria de Educação Especial, 2007.

LANDAU, E. A coragem de ser superdotado. 1. ed. São Paulo: Arte e ciência, 2002.

OLIVEIRA, M. E.; STOLTZ, T. Teatro na escola: consideraçôes a partir de Vigotski. In: Educar, Curitiba, n. 36 , p. 77-93, 2010

PISKE, F. H. R. Diversidade e inclusão: o direito à educação de alunos superdotados. In: X Congresso Nacional De Educaçao - Educere - I Seminário Internacional De Representaçóes Sociais, Subjetividade De Educaçao- Sirsse, 2011, Curitiba. Anais. Curitiba: X Congresso nacional de educação - EDUCERE - I Seminário internacional de representaçôes sociais, subjetividade de educação- SIRSSE. p. 151-161.

PISKE, F. H. R. O desenvolvimento socioemocional de alunos com altas habilidades/superdotaçáo (AH/ SD) no contexto escolar: contribuiçōes a partir de Vygotsky. 146 f. Dissertação (Mestrado em educação)- Setor de Educação, Universidade Federal do Paraná, Curitiba, 2013.

PISKE, F. H. R. Criatividade e inovação na educação de superdotados. In: PISKE, F. H. R. et al. Altas habilidades/ superdotação: criatividade e emoção. Curitiba: Juruá, 2014.

PISKE, F. H. R.; STOLTZ, T. Criatividade na escola: a necessidade de reavaliar as práticas educacionais aos alunos superdotados. In: Criatividade na escola: o desenvolvimento de potencialidades, altas habilidades/superdotação (AH/SD) e talentos. Curitiba: Juruá, 2013.

PISKE, F. H. R.; STOLTZ, T.; CAMARGO, D. Emoçóes e sentimentos de crianças superdotadas no contexto escolar: contribuiçôes a partir de Vigotski. In: PISKE, F. H. R. et al. Altas habilidades/superdotaçáo: criatividade e emoção. Curitiba: Juruá, 2014. p. 163- 183.

PISKE, F. H. R.; STOLTZ, T.; MACHADO, J. Creative Educational Practices for Inclusion of gifted children. In: Creative Education, v. 5, p. 803-808, 2014.

REIS. et al. Mediação pedagógica: reflexốes sobre o olhar estético em contexto de escolarização formal. Psicologia: reflexão e crítica, Florianópolis, v. 17, n. 1, p. 51-60, 2004.

SABATELLA, M. L. P. Talento e superdotação: problema ou solução?. 2. Ibpex: Curitiba, 2008.

SAMPIERI, R. H.; COLLADO, F. C.; LUCIO, M. P. B. Metodologia de pesquisa. 5. ed. Porto Alegre: Penso, 2013.

STOLTZ, T. et al. Creativity in Gifted Education: Contributions from Vygotsky and Piaget. Creative Education, v. 6, p. 64-70, 2015. Disponível em: <http://file.scirp.org/pdf/CE_2015011416262533.pdf>. Acesso em: 29 nov. 2015

Revista Educação Especial | v. 30 | n. 58 | p. 441-454 | maio/ago. 2017

Santa Maria

Disponível em: <http://www.ufsm.br/revistaeducacaoespecial> 
STOLTZ, T.; WEGER, U. Piaget and Steiner: science and art in the process of formation. Research on Steiner Education (RoSE), Germany, v.3, n.1, p.134 -145, July 2012.

STOLTZ, T.; WEGER, U. O pensar vivenciado na formação de professores. Educar em Revista. Curitiba, n. 56, p. 67-83, 2015.

TRIVIÑOS, A. N. S. Introduçáo à pesquisa em ciências sociais: a pesquisa qualitativa em educação. 1. ed. São Paulo: Atlas, 2013.

TOASSA, G. Emoçóes e vivências em Vigotski. 1.ed. Campinas: Papirus, 2011.

VALENTIM, B. F. B.; VESTENA, C. L. B.; NEUMANN, P. Educadores e estudantes: um olhar para a afetividade nas Altas habilidades/superdotação. Revista Educação Especial, Santa Maria, v. 27, n. 50, p. 713- 723, set./ dez. 2014

VEIGA, M.; STOLTZ, T. O pensamento de Rudolf Steiner no debate científico, 1.ed. Campinas: Alínea, 2014.

VIGOTSKI, L. S. Psicologia da arte. 1. ed. São Paulo: Martins Fontes, 2001.

VIGOTSKI, L. S. Imaginaçáo e criação na infância: ensaios psicológicos - livro para professores. 1. ed. São Paulo: Atica, 2009.

VIGOTSKI, L. S. Psicologia Pedagógica. 3.ed. São Paulo: Martins Fontes, 2010.

VIRGOLIM, A, M. R. A criança superdotada e a questão da diferença: um olhar sobre suas necessidades emocionais, sociais e cognitivas. Linhas Criticas, Brasília, v. 9, n. 16, p. 13- 31, 2003.

VIRGOLIM, A, M. R. Altas habilidades/superdotaçáo: encorajando potenciais. Brasília: Ministério da Educação: Secretaria da Educação Especial, 2007.

VIRGOLIM, A, M. R. A educação de alunos com Altas habilidades/superdotação em uma perspectiva inclusiva. In: MOREIRA, L. C.; STOLTZ, T. (Org.) Altas habilidades/superdotaçáo: talento, dotação e educação. Curitiba: Juruá, 2012.

ZANELLA, A. V. et al. Concepçôes de criatividade: movimentos em um contexto de escolarização formal. Psicologia em estudo. Maringá, v. 8, n.1, p. 143-150, 2003.

ZANELLA, A. V. et al. Movimentação de objetivação e subjetivação mediado pela criação artística. Psico-UFS. Florianópolis, v. 10, n. 2, p. 191-199, 2005.

\section{Notas}

${ }^{1}$ Com o intuito de proteger a identidade dos participantes, foram adotados nomes fictícios.

\section{Correspondência}

Tania Stoltz - Universidade Federal do Paraná, Setor de Educação, Departamento de Teoria e Fundamentos da Educação. General Carneiro Edif. D. Pedro I - Departamento de Teoria e Fundamentos da Educação - Centro. CEP: 80060-150. Curitiba, Paraná, Brasil.

E-mail: cris.lm18@gmail.com - tania.stoltz795@gmail.com

Recebido em 07 de julho de 2016

Aprovado em 21 de dezembro de 2016 